\title{
Aspects of psychology in sports medicine
}

\author{
Michael Greenspan PhD, Peggy Fitzsimmons MS and Stuart Biddle* PhD
}

Arizona State University (Counselling and Consultation), Tempe, Arizona 85287, USA and *School of Education, University of Exeter, Devon, UK

\begin{abstract}
Psychology's impact as an ergogenic aid across sports and competitive levels has been well documented. In addition, exercise can play a major role in disease prevention and health enhancement while also enhancing psychological well-being. In addition to its preventive value, exercise is being recognized as a valuable therapeutic tool. Like most therapeutic modalities, however, exercise also has some potentially negative qualities.
\end{abstract}

Keywords: Clinical sport psychology, injury rehabilitation, addictive exercising, substance abuse, eating disorders, over-training

Sports medicine uses psychological principles in the treatment of numerous clinical disorders and various aspects of health, and nowhere is there a more prominent merging of psychology, physiology, medicine and sports than in the area of sports medicine.

Competitive athletes have become well aware of the significant impact psychology has on the enhancement of performance. Its impact as an ergogenic aid in sport has been well documented ${ }^{1-3}$. The recreational exerciser also understands the relationship between exercise and an increased sense of well-being' and this effect has been shown to be a crucial motivator in exercise adherence.

Exercise can play a major role in both disease prevention and health enhancement ${ }^{5}$. For instance, the value of exercise in the treatment of diseases such as diabetes mellitus ${ }^{6}$ and asthma ${ }^{7}$ has been documented. Exercise can be an effective therapy for hypertension ${ }^{8}$, has consistently been shown to relate inversely to the incidence of coronary heart disease $^{9,10}$, and can facilitate weight control ${ }^{11}$. Exercise can also be effective in enhancing psychological well-being. For instance, exercise has been found to diminish anxiety ${ }^{12}$, depression ${ }^{13,14}$ and reactivity to psychosocial stressors ${ }^{15}$.

Exercise also has some potentially negative qualities. We now recognize the addictive potential of exercise, and 'burn out' can lead to overuse injuries, decreased immune functioning and psychological symptoms resembling depression. Last, the incidence is increasing of both substance abuse (e.g. alcohol, steroids and caffeine) and pathological

Address for correspondence: Dr M. Greenspan, Arizona State University, Counselling and Consultation Services, Tempe, Arizona 85287, USA

(C) 1991 Butterworth-Heinemann Ltd 0306-3674/91/040178-03 weight control techniques (e.g. diuretics, starvation and self-induced vomiting) as attempts to enhance performance.

\section{Injury-related issues}

Sports injuries can seriously threaten the patient's ability to exercise or compete and, in such situations, physicians need to be sensitive to the patient's response to injury, including loss of one's main source of self-esteem and identity. Little ${ }^{16}$ posited that overly ego-involved athletes may suffer an 'athletic neurosis' which he described as a bereavement reaction to the loss of a part of the self, the overvalued physical prowess. This places the athlete in a vulnerable state, leading to excessive difficulties in the event of actual or threatened deprivation (e.g. injury), especially if it is abrupt or unexpected. This is more prevalent in younger athletes, competitive athletes, and those engaging in 'addictive exercise behaviours'. Rotella and Heyman ${ }^{17}$ described the process athletes suffering a serious injury will typically experience. This involves: (1) disbelief, isolation and denial of the severity of the injury; (2) anger, possibly rage; (3) going through a 'bargaining' process; (4) sadness and depression; and (5) eventual acceptance of the loss. Patients stuck in the stage of denying the severity of the injury and those accepting the injury 'too easily' or 'too quickly' are often avoiding the significance of the injury. They may benefit from consultation.

After injury exercisers may be concerned about their athletic capability. Encouraging them to focus on doing their best, as opposed to winning versus losing, is critical. Focusing on one's own performance within the rehabilitation process, as opposed to comparing it to pre-injury levels, will enable the athlete to view his/her rehabilitation more realistically.

\section{Addictive-like behaviour patterns}

Addictive exercising

Exercisers who disregard strict medical advice may risk serious injury by exercising. Such individuals may switch activities if injury dictates, and appear overly 'ego-involved' in their exercising. In other words, they base a great deal of their identity and self-esteem on taking part in a particular activity. At this point, we must caution that some time and 
clinical skill is required to determine when someone is 'over' involved. Physicians need to discuss this with their patients, otherwise the ability to treat the problem is severely compromised. It is also important to understand that making the correct determination as to whether or not one is overly ego-involved is not the goal - the goal is to address the issue as a possibility and to work closely with the patient.

Veale $^{18}$ has suggested a set of diagnostic criteria for the syndrome of 'exercise dependence', and these are outlined in Table 1. He distinguishes between two types of exercise dependence: primary and secondary. Primary exercise dependence exists when exercise is an end in itself, with any associated weight loss or manipulations of diet being for the enhancement of performance. Secondary exercise dependence exists when the dependence is related to an eating disorder such as anorexia nervosa or bulimia nervosa.

Although exercise dependence is epidemiologically trivial it is, of course, a potentially serious clinical issue. Preliminary data from the UK on 20 subjects believed to have severe exercise dependence showed that they were predominantly in higher socioeconomic categories, and had a sense of 'compulsion' before exercising. Nearly all of these subjects reported withdrawal symptoms on stopping their daily routine, with symptoms reported of depression, irritability, guilt, insomnia and anxiety. Most of the subjects reported social problems associated with their dependence ${ }^{19}$.

\section{Substance abuse}

Some athletes, particularly those overly egoinvolved, are at risk from using/abusing what are believed to be performance-enhancing drugs, e.g. steroids, $\beta$-blockers, diuretics or other substances such as alcohol, marijuana and cocaine. While identifying those patients likely to be using certain 'performance enhancing' drugs may not be difficult,

Table 1. Diagnostic criteria for exercise dependence proposed by Veale $^{19}$. (Reproduced with permission from Dr D. Veale)

A. Narrowing of repertoire leading to stereotyped pattern of exercise with a regular schedule once or more daily

B. Excess, with the individual giving increased priority over other activities to maintaining the pattern of exercise

C. Increased tolerance to the amount of exercise performed over the years

D. Withdrawal symptoms related to a disorder of mood following the cessation of the exercise schedule

E. Relief or avoidance of withdrawal symptoms by further exercise

F. Subjective awareness of a compulsion to exercise

G. Rapid reinstatement of the previous pattern of exercise and withdrawal symptoms after a period of abstinence

Associated features

$\mathrm{H}$. Either the individual continues to exercise despite a serious physical disorder known to be caused, aggravated or prolonged by exercise and is advised as such by a health professional, or the individual has arguments or difficulties with his/her partner, family, friends or occupation

I. Self-inflicted loss of weight by dieting as a means towards improving performance identifying those patients at risk for substance abuse may prove to be far more difficult. An athlete or recreational exerciser with a history of substance abuse may be at risk in the event of serious injury. The risk is higher if the patient: (1) has not received counselling for the addiction; (2) does not have a social support network recognizing the link of their self-esteem with their athleticism; and/or (3) appears stuck in the denial phase of a grief process or has accepted injury 'too easily'. Identifying athletes competing in 'strength' activities (weightlifters, football linemen and linebackers, rugby players, sprinters, shotputters and discus, hammer and javelin throwers) as being in high-risk groups for abusing anabolic steroids may also be helpful. Discussing the potential for future use is essential in establishing an effective doctor-patient relationship.

In addition, sport psychologists may find themselves in a position where they are required to consult with participants who are taking banned substances. Although clinical guidelines have been suggested by numerous authors, no ethical stance has been clearly established for such situations ${ }^{20}$.

\section{Eating disorders}

The high prevalence of pathological weight control techniques has been documented in elite gymnasts ${ }^{21}$, high school and collegiate wrestlers ${ }^{22}$, youth swimmers $^{23}$, bodybuilders ${ }^{24}$ and college athletes ${ }^{25,26}$. Rosen and Hough ${ }^{21}$ found that $62 \%$ of collegiate level gymnasts $(n=42)$ used some form of pathogenic weight control technique, such as fasting, selfinduced vomiting, diet pills, laxatives or diuretics. Dummer et al. ${ }^{23}$ found that $15.4 \%$ of 900 9-18-yearold female swimmers $(25.4 \%$ of the postmenarchal girls) used at least one pathological form of weight control. Anecdotal evidence also exists which suggests athletes in diving, tennis, figure skating, distance running, boxing, judo and weightlifting also engage in such behaviour.

It appears that participants in activities in which size, weight and/or body image may be crucially related to outcome are considered to be at risk. Identifying recreational exercisers and athletes with eating disorders may prove especially difficult. Such individuals are often reluctant to inform their physician of their difficulties as they feel shame and inadequacy. Consequently, in addition to being aware of the numerous medical sequelae physicians need to be aware of the psychological correlates of eating disorders. Preoccupation with food and/or body weight, body image distortion, self-esteem deficits, depressive symptomatology, fears of biological and/or psychological maturity, and the presence of family conflicts are common elements in patients with eating disorders. It is important to note that the patient may not alert the physician and may appear psychologically healthy. In fact, many present as the classic 'over achiever' from a middle to upper class background. Again, the responsibility must rest on the physician to conduct an extensive interview if any of the above symptoms are present. 


\section{Overtraining issues}

Overuse injuries, 'staleness' or 'burnout', depressive symptoms, a lack of variety and breaks in patients' training regimens, and/or decreases in patients' immune functioning may all identify patients at risk from overtraining. Silva ${ }^{27}$ provides a useful distinction between 'staleness', 'overtraining' and 'burnout'. Staleness is 'an initial failure of the body's adaptive mechanisms to cope with the psychophysiological stress caused by training stimuli'; 'overtraining' is defined as 'repeated failure of the body's adaptive mechanisms to cope with chronic training stress' and 'burnout' is an 'exhaustive psychophysiological response exhibited as a result of frequent, sometimes extreme, but generally ineffective efforts to meet excessive training and competitive demands'. Correct diagnosis enhances treatment. In addition to medical treatment a break from training, more efficient training and setting short-term goals may be sufficient to 'rejuvenate' the patient. If 'burnout' persists, consultation with a sport psychologist may be appropriate.

\section{Chronic pain}

On occasion, athletes will report pain that persists without clear medical cause. Initially, it is important to investigate any potential benefits of being hurt or injured. Sanderson ${ }^{28}$ outlined a number of potential benefits, including face saving, escape, passiveaggressiveness against parental pressure and avoidance of training. In addition, physical injury can provide struggling athletes with a more socially acceptable reason for leaving a team or not playing well. Often such athletes will have a history of numerous somatic complaints, may be unable to identify goals for treatment and recovery, will show poor treatment compliance, and/or may go from doctor to doctor until one is found who will provide the medical attention and treatment desired.

\section{References}

1 Greenspan M, Feltz D. The effects of psychological interventions with athletes in competitive situations: a review. Sport Psychol 1989; 3: 219-36.

2 Whelan J, Meyers A, Berman J, Bryant V, Mellon W. Meta-Analysis of Cognitive-Behavioral Interventions for Performance Enhancement in Sport. Presentation made at the 97th Annual Meeting of the American Psychological Association, New Orleans, USA: APA, 1989.

3 Feltz D, Landers D. The effects of mental practice on motor skill learning and performance: a meta-analysis. J Sport Psychol 1983; 5: 25-57.
4 Koslow R. Age related reasons for expressed interest in exercise and weight control. J Appl Soc Psychol 1988; 18: 349-54.

5 Biddle SJH, Fox KR. Exercise and health psychology: emerging relationships. Br J Med Psychol 1989; 62: 205-16.

6 Ekoe J. Overview of diabetes mellitus and exercise. Med Sci Sport Exerc 1989; 21: 353-5.

7 Gilbert IA, Fouke IM, McFadden ER. The effect of repetitive exercise on airway temperatures. Am Rev Resp Dis 1990; 142: 826-31.

8 Raglin J, Morgan W. Influence of exercise and quiet rest on state anxiety and blood pressure. Med Sci Sport Exerc 1987; 19: 456-63.

9 Paffenbarger R, Hyde R, Wing A, Hsieh C. Physical activity, all-cause mortality and longevity of college alumni. New Engl $J$ Med 1986; 314: 605-13.

10 Powell K, Thompson P, Caspersen C, Kendrick J. Physical activity and the incidence of coronary heart disease. Ann Rev Publ Health 1987; 8: 253-87.

11 Brownell $\mathrm{K}$. Obesity: understanding and treating a serious, prevalent and refractory disorder. J Consult Clin Psychol 1982; 50: $820-40$.

12 Petruzello S, Landers D. Effects of exercise on anxiety and mood: a meta-analysis. Proceedings of 36th Annual Meeting of the American College of Sports Medicine, Baltimore, USA: ACSM, 1989.

13 Dishman R. Medical psychology in exercise and sport. Med Clin North Am 1985; 69: 123-43.

14 Ossip-Klein D, Doyne E, Bowman E, Osborn K, McDougallWilson I, Neimeyer R. Effects of running or weight lifting on self-concept in clinically depressed women. I Consult Clin Psychol 1989; 57: 158-61.

15 Crews D, Landers D. A meta-analytic review of aerobic fitness and reactivity to psychosocial stressors. Med Sci Sports Exerc 1987; 19: 5114-20.

16 Little J. The athletic neurosis: a deprivation crisis. Acta Psychol Scand 1969; 45: 187.

17 Rotella RJ, Heyman SR. Stress, injury, and the psychological rehabilitation of athletes. In: Williams J, ed. Applied Sport Psychology: Personal Growth to Peak Performance. Palo Alto, California, USA: Mayfield Publishing Company, 1986.

18 Veale D. Exercise dependence. Br J Addict 1987; 82: 735-40.

19 Veale D, Le Fevre K. A Survey of Exercise Dependence. Proceedings of the Sport, Health, Psychology and Exercise Symposium, Bisham Abbey National Sports Centre, London: The Sports Council, 1988.

20 Biddle SJH, Bull SJ, Seheult C. Ethical and Professional Issues in Contemporary British Sport Psychology. The Sport Psychologist, in press.

21 Rosen L, Hough D. Pathogenic weight-control behaviors of female college gymnasts. Phys Sports Med 1988; 16: 141-5.

22 Steen SN, Brownell KD. Patterns of weight loss and regain in wrestlers: has the tradition changed? Med Sci Sports Exerc 1990; 22: 762-8.

23 Dummer G, Rosen L, Heusner W, Roberts P, Counsilman J. Pathogenic weight control behaviors of young competitive swimmers. Phys Sportsmed 1987; 15: 75-84.

24 Borgen J, Corbin C. Eating disorders among female athletes. Phys Sports Med 1987; 15: 88-95.

25 Black DR, Burckes-Miller ME. Male and female college athletes: use of anorexia nervosa and bulimia nervosa weight loss methods. Res $Q$ Exerc Sport 1988; 59: 252-6.

26 Rosen LW, McKeag DB, Hough DD, Curley V. Pathogenic weight control behaviour in female athletes. Phys Sportsmed 1986; 14: 79-86.

27 Silva JM. An analysis of the training stress syndrome in competitive athletics. J Appl Sport Psychol 1990; 2: 5-20.

28 Sanderson $\mathrm{F}$. The psychology of the injury prone athlete. $\mathrm{Br} J$ Sports Med 1977; 11: 56. 